\title{
Food shopping habits, physical activity and health-related indicators among adults aged $\geq 70$ years
}

\author{
Janice L Thompson ${ }^{1, *}$, Georgina Bentley ${ }^{1}$, Mark Davis ${ }^{1}$, Jo Coulson ${ }^{1}$, Afroditi Stathi ${ }^{2}$ \\ and Kenneth R Fox ${ }^{1}$ \\ ${ }^{1}$ Centre for Exercise, Nutrition and Health Sciences, School for Policy Studies, University of Bristol, \\ 8 Priory Road, Bristol BS8 1TZ, UK: ${ }^{2}$ School for Health, University of Bath, Bath, UK
}

Submitted 27 August 2010: Accepted 25 February 2011: First published online 6 May 2011

\begin{abstract}
Objective: To investigate the food shopping habits of older adults in the UK and explore their potential associations with selected health-related indicators.

Design: A cross-sectional study including objectively measured physical activity levels, BMI, physical function and self-reported health status and dietary intake. Setting: Bristol, UK.

Subjects: A total of 240 older adults aged $\geq 70$ years living independently.

Results: Mean age was $78 \cdot 1$ (sD $5 \cdot 7$ ) years; $66 \cdot 7 \%$ were overweight or obese and $4 \%$ were underweight. Most $(80 \cdot 0 \%)$ carried out their own food shopping; $53.3 \%$ shopped at least once weekly. Women were more likely to shop alone $(P<0 \cdot 001)$ and men more likely to shop with their spouse $(P<0 \cdot 001)$. Men were more likely than women to drive to food shopping $(P<0 \cdot 001)$, with women more likely to take the bus or be driven $(P<0 \cdot 001)$. Most reported ease in purchasing fruit and vegetables $(72.9 \%)$ and low-fat products $(67.5 \%) ; 19 \cdot 2 \%$ reported low fibre intakes and $16 \cdot 2 \%$ reported high fat intakes. Higher levels of physical function and physical activity and better general health were significantly correlated with the ease of purchasing fresh fruit, vegetables and low-fat products. Shopping more often was associated with higher fat intake $(P=0 \cdot 03)$; higher levels of deprivation were associated with lower fibre intake $(P=0 \cdot 019)$. Conclusions: These findings suggest a pattern of food shopping carried out primarily by car at least once weekly at large supermarket chains, with most finding high-quality fruit, vegetables and low-fat products easily accessible. Higher levels of physical function and physical activity and better self-reported health are important in supporting food shopping and maintaining independence.
\end{abstract}

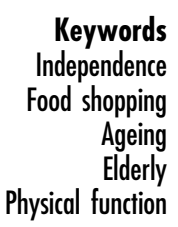

Older adults comprise the fastest-growing population group, with WHO projecting a total of $1 \cdot 2$ billion people over the age of 60 years by $2025^{(1)}$. In 2001, there were approximately 1 million adults aged $\geq 85$ years in England and Wales, with this number projected to increase to 2.5 million (or $4 \%$ of the total population) by $2031^{(2)}$. In these countries there has been a 14-fold and 23-fold increase in the number of male and female centenarians, respectively, over the past 50 years of the 20th century ${ }^{(3)}$. This substantial increase in the number of older adults has important implications for individuals, families and health- and social-care systems, as there is the potential for many people to live a greater number of years in poor health.

Older adults are at greatest risk for lifestyle-related diseases, including type 2 diabetes, CHD, stroke, hypertension and certain cancers. In the UK, $41 \%$ of men and $38 \%$ of women aged $60-74$ years suffer from a chronic illness that limits daily activities; this increases to $58 \%$ of men and $62 \%$ of women over the age of 75 years ${ }^{(4)}$. Interventions incorporating healthy eating and regular physical activity are known to be effective in reducing the risks of several chronic diseases ${ }^{(5,6)}$, emphasising the significant contribution of these lifestyle factors towards maintaining good health throughout an individual's life span.

Malnutrition is estimated to affect $>10 \%$ of older adults in the $\mathrm{UK}^{(7)}$. Data from the Health Survey for England indicate that $0.9 \%$ of adults aged $65-74$ years and $1.6 \%$ of those aged $\geq 75$ years are underweight. Conversely, $76.2 \%$ and $68.9 \%$ of adults in these respective age groups are considered overweight or obese ${ }^{(8)}$. Limited access to affordable healthy foods, difficulties in acquiring, preparing and consuming healthy meals, existing illness, medication use, age-related physiological changes, low levels of physical activity and financial difficulties are 
important contributors to undernourishment, overweight and obesity in older adults ${ }^{(9)}$. Currently, there is little published research on the food shopping habits of older adults in the UK and how these habits may be associated with the quality of dietary intake, levels of overweight and physical activity, and overall health.

The ability to care for oneself and remain independent is extremely important to older people ${ }^{(10)}$, with many reporting a strong desire to stay in their own home for as long as possible ${ }^{(11)}$. Food shopping is not only a necessary activity of daily living but it also contributes to one's sense of independence and can become increasingly difficult for older people as they experience declines in health, mobility and the ability to drive a car. Carrying groceries, limited options for transport and financial constraints all contribute to the challenges experienced by older people when purchasing food ${ }^{(12)}$. Research conducted in North America has shown that food shopping is restricted to the immediate neighbourhood of older adults and proximity to food shops contributes to their well-being ${ }^{(13,14)}$. However, in the UK, an increasing number of local food shops are closing and larger supermarkets located outside local neighbourhoods are appearing more frequently. It is unclear how this change may affect the ability of older adults to purchase healthy foods and maintain adequate nutritional intake, good health and independence.

The primary aims of the present paper are to: (i) describe the food shopping habits of a sample of older adults (aged $\geq 70$ years) living in the UK; and (ii) explore potential associations between food shopping habits and selected health-related indicators, including objectively measured physical activity levels, BMI, physical function and self-reported health status and dietary intake.

\section{Experimental methods}

\section{Study design}

The present study is part of the Older People and Active Living (OPAL) project, a community-based descriptive observational study that aimed to provide data on physical activity patterns and their determinants among independent older adults living in Bristol, UK. Ethical approval was granted by the Bristol Southmead NHS Research Ethics Committee (Reference no. 06/Q2002/127).

\section{Sampling and recruitment}

Complete details of sampling, recruitment and inclusion or exclusion criteria have been published previously ${ }^{(15)}$. The aim was to provide a sample that was broadly representative of the city of Bristol in relation to socio-economic position and access to amenities. To achieve this, twelve general medical practices within the city were selected to represent areas of low, medium and high deprivation, as defined by the Index of Multiple Deprivation (IMD) score for each practice ${ }^{(16)}$, and low or high proximity to the nearest store. A total of 1328 individuals aged $\geq 70$ years at the time of recruitment were randomly selected from the twelve practice patient lists, and 1170 individuals who qualified for the study were mailed an invitation, an information pamphlet and a consent form. Response rate to the invitation was $54 \cdot 6 \%$ (725 of 1170), with 240 participants $(47 \cdot 9 \%$ female) providing written informed consent and completing the study. Sample size was based on detecting a significant difference in the physical activity levels of participants in the three tertiles of $\mathrm{IMD}^{(15)}$. The results reported in the present paper represent secondary analyses from a study that was primarily designed to detect differences in physical activity; thus, no formal power calculations were carried out to detect differences in food shopping among IMD tertiles. These secondary analyses on food shopping should therefore be considered exploratory.

\section{Measures}

Data were collected during 2007-2008 over two home visits (generally $8 \mathrm{~d}$ apart) for each participant. The Neighborhood and Quality of Life for Seniors Study Questionnaire $^{(17)}$ included many items such as demographics (age, gender, income, marital status, education, current disease treatment and car ownership) and 'neighbourhood food environment' (availability and ease of purchase of fresh fruit, vegetables and low-fat foods). As this questionnaire was developed in the USA, questions were modified, as necessary, for UK delivery. Questions about the perceived distance to the nearest facilities (categorised walking time, min) were originally sourced from the 2002 version of the Neighbourhood Environment Walkability Scale ${ }^{(18)}$, with questions added on the frequency of facility use and normal mode of transport to give richer contextual information.

Household food security, defined as access to enough food by all members at all times for an active, healthy life, was assessed using the US Household Food Security Hunger Survey Module ${ }^{(19)}$. The 12-Item Short-Form Health Survey was used to measure perceptions of general health and functional health status ${ }^{(20)}$. Dietary intake was measured using the Dietary Assessment for Nutrition Education tool, which has been validated in UK adults and gives a score for low, medium and high dietary intakes of fibre, total fat and unsaturated fat ${ }^{(21)}$. The low-fat category represents a fat intake of $\leq 83 \mathrm{~g} / \mathrm{d}$, corresponding to $35 \%$ of the energy RDA for an average woman. The high-fat category represents a fat intake $>122 \mathrm{~g} / \mathrm{d}$, corresponding to $40 \%$ of the energy RDA for an average man. The low-fibre category corresponds to a fibre intake of $\leq 20 \mathrm{~g} / \mathrm{d}$ and the high-fibre category corresponds to $>30 \mathrm{~g} / \mathrm{d}$. The unsaturated fat score is categorised empirically into low, medium and high levels of unsaturated fat contributed by the added fat used for spreads and cooking in the diet. Responses to questions 
were elicited using large-font prompt cards and recorded by interviewers.

Physical activity (steps/d) was assessed using accelerometry and described previously ${ }^{(15)}$. Briefly, participants wore an Actigraph GT1M monitor (Pensacola, FL, USA) on a belt for $7 \mathrm{~d}$ and kept a log of daily journeys, including frequency, mode of transport and purpose. GT1M monitors were programmed to record activity in $10 \mathrm{~s}$ epochs, producing both activity count and step count data. Physical function was assessed using the Short Physical Performance Battery (SPPB) ${ }^{(22)}$, which measures lower-extremity function in older adults. Height and weight were measured once using a Seca Leicester stadiometer and Seca portable scale, respectively (Northampton, UK); BMI $\left(\mathrm{kg} / \mathrm{m}^{2}\right)$ was calculated from measured height and weight.

\section{Statistical analyses}

All statistical analyses were performed using the Statistical Package for the Social Sciences statistical software package version 16.0 (SPSS Inc., Chicago, IL, USA). Descriptive statistics (means, SD, frequencies and proportions) were generated for all variables. Group comparisons were made using independent $t$ tests for continuous data, $\chi^{2}$ tests for categorical data and Mann-Whitney $U$ tests for ordinal data. Spearman's correlations $(\rho)$ were used to assess the relationships between variables. Significance was set at $P<0.05$.

\section{Results}

The majority of the 240 participants were white ( $n$ 230; $95 \cdot 8 \%)$, with two $(0 \cdot 8 \%)$, four $(1.7 \%)$ and two $(0 \cdot 8 \%)$ reporting race as Black/Afro-Caribbean, Asian and other, respectively. Table 1 includes selected demographic characteristics. Mean age was 78.1 (SD 5.7) years, with $11.7 \%$ of participants aged $\geq 85$ years. Approximately $67 \%$ of OPAL participants were overweight or obese; this compares with $76 \cdot 2 \%$ of adults aged $65-74$ years and $68.9 \%$ of adults aged $\geq 75$ years being overweight or obese nationally ${ }^{(23)}$. Almost $4 \%$ of OPAL participants were underweight. This is slightly higher than the prevalence of $0.9-1.5 \%$ reported in the Health Survey for England $^{(23)}$ for adults aged $65-74$ years and $\geq 75$ years, respectively.

The IMD scores for participants' residence were reasonably representative of the IMD distribution in England, with $22 \cdot 1 \%, 27 \cdot 9 \%, 31 \cdot 3 \%$ and $18 \cdot 7 \%$ of the OPAL sample falling into the lowest to highest national quartiles, respectively ${ }^{(24)}$. Almost all participants reported being food secure, with $91.7 \%$ reporting having enough food to eat and $4.6 \%$ reporting having enough food but not always the type of food they would like to eat.

Almost $83 \%$ of OPAL participants self-reported their health as good, very good or excellent. The most commonly reported disease was hypertension (48.8\%), which is less than its overall prevalence in the UK; $52 \cdot 1 \%$ and $68.4 \%$ of adults aged $65-74$ and $\geq 75$ years, respectively, have hypertension ${ }^{(23)}$. In addition, $21 \cdot 7 \%$ of OPAL women and $32.0 \%$ of men reported having a heart condition; this is comparable to the prevalence of CHD among adults aged $\geq 75$ years in the UK, with $19.3 \%$ of women and $28 \cdot 6 \%$ of men having $\mathrm{CHD}^{(25)}$. The proportion of OPAL participants with osteoarthritis was also similar to its national equivalent ${ }^{(26)}$.

Physical function as measured by the SPPB was relatively high, with a mean score of $9 \cdot 7$ out of a possible 12 points; men had significantly higher physical function scores than women $(P=0 \cdot 004)$. Detailed physical activity results are reported elsewhere ${ }^{(15)}$. In summary, men were significantly more active than women with a mean of 4714.0 (SD 227.2) v. 4182.9 (SD 233.5) steps/d, although almost none met the current recommendations for physical activity.

Results related to food shopping habits are reported in Table 2. Most participants $(80.0 \%)$ conducted their food shopping by themselves or with someone else. Women were more likely than men to shop alone $(50 \cdot 4 \% v$. $28 \cdot 8 \%, P<0 \cdot 001)$, with men more likely than women to report shopping with their spouse $(48 \cdot 8 \%$ v. $24 \cdot 3 \%$, $P<0 \cdot 001)$. The most commonly reported main food shopping venue was the nearest supermarket $(33 \cdot 3 \%)$. The main food shopping venues frequented by 115 ( $86 \%$ ) of the 133 participants who reported the name of their main food shop included one of the four largest supermarket chains in the UK (Tesco, Asda, Sainsbury's and Morrisons) or an upmarket national chain (Waitrose).

The perceived walking distance to the main food shopping venue was reported to be at least $31 \mathrm{~min}$ in $40.8 \%$ of participants. Over half $(53 \cdot 3 \%)$ reported a frequency of at least once weekly for their main food shopping, with $50.3 \%$ driving to or being driven to their main food shopping venue. Men were more likely than women to drive to their food shopping venue $(P<0 \cdot 001)$, with women more likely to be passengers $(P<0 \cdot 001)$ or to take the bus $(P<0 \cdot 001)$. This finding is consistent with the number of cars reported per household in the present study, with men reporting significantly more cars in their household than women (men: mean $=1.09$ cars, range $=0-6 ;$ women: mean $=0.73$ cars, range $=0-2 ; P<0 \cdot 001)$.

The majority of participants reported infrequently or never' using restaurants (78.7\%), fast-food outlets $(82 \cdot 5 \%)$ or pubs $(83.3 \%)$, suggesting the predominance of food shopping to procure food. Bakeries were more frequently used, with $13 \cdot 8 \%$ going to a bakery at least once weekly and $12.5 \%$ going at least once monthly; $60.4 \%$ reported going to a bakery infrequently or never (data not shown).

Table 3 includes the findings related to the ease of purchasing and availability of fruit, vegetables and low-fat food products, and to intakes of fibre, fat and unsaturated fat. 
Table 1 Demographics of 240 older adults aged $\geq 70$ years living in Bristol, UK

\begin{tabular}{|c|c|c|c|c|c|c|}
\hline & \multicolumn{2}{|c|}{ Women ( $n$ 115) } & \multicolumn{2}{|c|}{ Men ( $n$ 125) } & \multicolumn{2}{|c|}{ Total $(n 240)$} \\
\hline & Mean & SD & Mean & SD & Mean & SD \\
\hline Age (years) & $78 \cdot 7$ & $5 \cdot 7$ & $77 \cdot 6$ & $5 \cdot 7$ & $78 \cdot 1$ & $5 \cdot 7$ \\
\hline \multicolumn{7}{|l|}{ Age distribution (years; \%) } \\
\hline $70 \cdot 0-74 \cdot 9$ & \multicolumn{2}{|c|}{$28 \cdot 7$} & \multicolumn{2}{|c|}{$42 \cdot 4$} & \multicolumn{2}{|c|}{$35 \cdot 8$} \\
\hline $75 \cdot 0-79 \cdot 9$ & \multicolumn{2}{|c|}{$28 \cdot 7$} & \multicolumn{2}{|c|}{$25 \cdot 6$} & \multicolumn{2}{|c|}{$27 \cdot 1$} \\
\hline $80 \cdot 0-84 \cdot 9$ & \multicolumn{2}{|c|}{$31 \cdot 3$} & \multirow{2}{*}{\multicolumn{2}{|c|}{$\begin{array}{l}20 \cdot 0 \\
12 \cdot 0\end{array}$}} & \multirow{2}{*}{\multicolumn{2}{|c|}{$\begin{array}{l}25 \cdot 4 \\
11 \cdot 7\end{array}$}} \\
\hline$\geq 85$ & \multicolumn{2}{|c|}{$11 \cdot 3$} & & & & \\
\hline Height $(\mathrm{cm})$ & $156 \cdot 5^{\star}$ & $6 \cdot 4$ & $170 \cdot 9$ & $7 \cdot 1$ & $164 \cdot 0$ & $9 \cdot 9$ \\
\hline Weight (kg) & $68 \cdot 3^{*}$ & $14 \cdot 6$ & $77 \cdot 9$ & $13 \cdot 6$ & $73 \cdot 3$ & $14 \cdot 9$ \\
\hline $\operatorname{BMI}\left(\mathrm{kg} / \mathrm{m}^{2}\right)$ & $27 \cdot 9^{\star}$ & $5 \cdot 7$ & $26 \cdot 6$ & $4 \cdot 0$ & $27 \cdot 2$ & 4.9 \\
\hline \multicolumn{7}{|l|}{ BMI distribution $\left(\mathrm{kg} / \mathrm{m}^{2} ; \%\right)$} \\
\hline Underweight $(<18.5)$ & \multirow{2}{*}{\multicolumn{2}{|c|}{$\begin{array}{r}3.5 \\
30 \cdot 4\end{array}$}} & \multicolumn{2}{|c|}{$4 \cdot 0$} & \multicolumn{2}{|c|}{$3 \cdot 8$} \\
\hline Normal weight (18.5-24.9) & & & \multicolumn{2}{|c|}{$28 \cdot 8$} & & \\
\hline Overweight $(25 \cdot 0-29 \cdot 9)$ & \multicolumn{2}{|c|}{$31 \cdot 3$} & & & & \\
\hline Obese $(\geq 30 \cdot 0)$ & & & & & & \\
\hline Educational level (\%)† & & & & & & \\
\hline Primary or middle school & & & & & & \\
\hline Secondary & & & & & & \\
\hline Tertiary & & & & & & \\
\hline $\mathrm{N} / \mathrm{A}$ & & & & & & \\
\hline IMD tertile (\%)‡ & & & & & & \\
\hline Low $(1 \cdot 9-12 \cdot 1)$ & & & & & & \\
\hline Middle $(12 \cdot 2-21 \cdot 1)$ & & & & & & \\
\hline High $(21 \cdot 2-76 \cdot 0)$ & & & & & & \\
\hline Marital status (\%) & & & & & & \\
\hline Married & & & & & & \\
\hline Widowed & & & & & & \\
\hline Divorced or separated & & & & & & \\
\hline Single and never married & & & & & & \\
\hline Living with a partner & & & & & & \\
\hline$N / A$ & & & & & & \\
\hline General health (\%) & & & & & & \\
\hline Excellent & & & & & & \\
\hline Very good & & & & & & \\
\hline Good & & & & & & \\
\hline Fair & & & & & & \\
\hline Poor & & & & & & \\
\hline N/A & & & & & & \\
\hline Current disease treatment $(\%$ & & & & & & \\
\hline Rheumatoid arthritis & & & & & & \\
\hline Osteoarthritis & & & & & & \\
\hline Hypertension & & & & & & \\
\hline Diabetes & & & & & & \\
\hline Heart condition & & & & & & \\
\hline Cancer & & & & & & \\
\hline Physical function score§ & $9 \cdot 2^{*}$ & $2 \cdot 3$ & $10 \cdot 1$ & $2 \cdot 3$ & $9 \cdot 7$ & $2 \cdot 4$ \\
\hline
\end{tabular}

IMD, Index of Multiple Deprivation; N/A, data not available.

*Significant difference between genders.

tHighest level of education achieved. Primary or middle-level education includes those who underwent some amount of schooling, but did not complete secondary school. Tertiary-level education includes college and university education.

$\ddagger$ Scores derived from participants' postcodes (a high score indicates a high level of deprivation).

\$The highest possible score achievable is 12 .

The majority of participants somewhat or strongly agreed that it was easy to purchase fresh fruit and vegetables, that they had access to a large selection of them and that they had access to fresh produce of high quality. However, $23 \cdot 4 \%, 31 \cdot 3 \%$ and $25 \cdot 0 \%$, respectively, somewhat or strongly disagreed with these statements. Although more than half also somewhat or strongly agreed that it was easy to purchase low-fat foods and that there was a large selection of low-fat products available, $21 \cdot 2 \%$ and $26 \cdot 3 \%$, respectively, somewhat or strongly disagreed with these statements. Almost $20 \%$ of participants reported a low fibre intake, with $16 \cdot 2 \%$ reporting a high fat intake. The majority $(91.7 \%)$ reported a medium-to-high intake of unsaturated fat. Significantly more women than men reported a low fat intake $(P=0 \cdot 015)$, with significantly more men than women reporting a medium fat intake $(P=0 \cdot 015)$.

Table 4 shows Spearman's rank order correlations $(\rho)$ between BMI, general health, physical function, physical activity levels (steps/d) and selected food shopping variables. There were weak but significant correlations between physical function, general health and physical 
Table 2 Food shopping habits of 240 older adults aged $\geq 70$ years living in Bristol, UK

\begin{tabular}{|c|c|c|c|}
\hline & Women $(n 115)$ & Men $(n 125)$ & Total $(n 240)$ \\
\hline & $\%$ & $\%$ & $\%$ \\
\hline \multicolumn{4}{|l|}{ Who does the shopping? } \\
\hline Do it myself or with someone else & $84 \cdot 3$ & $76 \cdot 0$ & $80 \cdot 0$ \\
\hline Someone does it for me & $7 \cdot 0$ & $16 \cdot 8$ & $12 \cdot 1$ \\
\hline A bit of both & $8 \cdot 7$ & $5 \cdot 6$ & $7 \cdot 1$ \\
\hline $\mathrm{N} / \mathrm{A}$ & 0.0 & $1 \cdot 6$ & $0 \cdot 8$ \\
\hline \multicolumn{4}{|l|}{ Who else shops with you or for you? } \\
\hline Spouse & $24 \cdot 3^{*}$ & $48 \cdot 8$ & $37 \cdot 1$ \\
\hline Family member & $16 \cdot 5$ & $13 \cdot 6$ & $15 \cdot 0$ \\
\hline Other & $5 \cdot 2$ & $1 \cdot 6$ & $3 \cdot 3$ \\
\hline Shop alone & $50 \cdot 4^{*}$ & $28 \cdot 8$ & $39 \cdot 2$ \\
\hline$N / A$ & $3 \cdot 5$ & $7 \cdot 2$ & $5 \cdot 4$ \\
\hline \multicolumn{4}{|l|}{ Where do you do your main food shopping? } \\
\hline Nearest supermarket & $33 \cdot 0$ & $33 \cdot 6$ & $33 \cdot 3$ \\
\hline Nearest convenience or grocery store & 3.5 & 0.0 & $1 \cdot 7$ \\
\hline Nearest mini or express supermarket & $2 \cdot 6$ & $4 \cdot 8$ & $3 \cdot 8$ \\
\hline Other shop & $29 \cdot 6$ & $24 \cdot 8$ & $27 \cdot 1$ \\
\hline Other shopping pattern & $7 \cdot 8$ & $10 \cdot 4$ & $9 \cdot 2$ \\
\hline $\mathrm{N} / \mathrm{A}$ & $23 \cdot 5$ & $26 \cdot 4$ & $25 \cdot 0$ \\
\hline \multicolumn{4}{|c|}{ Perceived walking distance to the main food shopping venue (min) } \\
\hline $1-5$ & $3 \cdot 5$ & $4 \cdot 0$ & $3 \cdot 8$ \\
\hline $6-10$ & $10 \cdot 4$ & $8 \cdot 8$ & $9 \cdot 6$ \\
\hline $11-20$ & $4 \cdot 3$ & $8 \cdot 8$ & $6 \cdot 7$ \\
\hline $21-30$ & $5 \cdot 2$ & $6 \cdot 4$ & $5 \cdot 8$ \\
\hline$\geq 31$ & $43 \cdot \overline{5}$ & $38 \cdot 4$ & $40 \cdot 8$ \\
\hline Do not know & 0.9 & $3 \cdot 2$ & $2 \cdot 1$ \\
\hline N/A & $32 \cdot 2$ & $30 \cdot 4$ & $31 \cdot 2$ \\
\hline \multicolumn{4}{|c|}{ Frequency of use of the main food shopping venue } \\
\hline Daily & $6 \cdot 1$ & $4 \cdot 8$ & $5 \cdot 4$ \\
\hline At least once weekly & $54 \cdot 8$ & $52 \cdot 0$ & $53 \cdot 3$ \\
\hline At least once monthly & $7 \cdot 8$ & $4 \cdot 0$ & $5 \cdot 8$ \\
\hline Infrequently & 0.0 & $4 \cdot 0$ & $2 \cdot 1$ \\
\hline Never & 3.5 & $4 \cdot 8$ & $4 \cdot 2$ \\
\hline $\mathrm{N} / \mathrm{A}$ & $27 \cdot 8$ & $30 \cdot 4$ & $29 \cdot 2$ \\
\hline \multicolumn{4}{|c|}{ Mode of transport to the main food shopping venue } \\
\hline Drive & $29 \cdot 6^{*}$ & $47 \cdot 2$ & $38 \cdot 6$ \\
\hline Driven & $19 \cdot 1^{*}$ & $4 \cdot 8$ & $11 \cdot 7$ \\
\hline Bus & $10 \cdot 4^{*}$ & $3 \cdot 2$ & $6 \cdot 7$ \\
\hline Walk & $8 \cdot 7$ & $10 \cdot 4$ & $9 \cdot 6$ \\
\hline $\mathrm{N} / \mathrm{A}$ & $32 \cdot 2$ & $34 \cdot 4$ & 33.4 \\
\hline
\end{tabular}

$\mathrm{N} / \mathrm{A}$, data not available.

${ }^{\star}$ Significant difference between genders.

activity (steps/d), indicating that higher physical function and better self-reported general health were associated with greater levels of physical activity. The ease of purchasing, extent of selection and quality of fresh fruit, vegetables and low-fat products were strongly intercorrelated and weakly but significantly correlated with higher physical function, higher physical activity and better self-reported general health. Participants who reported a stronger disagreement with the ease of purchasing, extent of selection and quality of fruit, vegetables and low-fat products were more likely to report walking a higher number of minutes to their main food shop. Higher levels of physical activity were associated with a higher frequency of use of the main food shopping venue, whereas walking for a higher number of minutes to the main food shop was associated with lower frequency of its use. Taking the bus, walking or cycling to the main food shop was associated with a greater frequency of use of the main food shop compared with using a $\operatorname{car}(\rho=-0 \cdot 402, P<0 \cdot 001, n$ 169).

There were very few significant correlations between fibre, fat and unsaturated fat intakes and other shopping and health-related variables (data not shown). Fat intake was weakly correlated with BMI, indicating an association between higher fat intake and lower BMI $(\rho=-0 \cdot 180$, $P=0 \cdot 013, n$ 192). Fat intake was also weakly correlated with the frequency of use of the main food shopping venue $(\rho=0 \cdot 185, P=0 \cdot 030, n 138)$, indicating that shopping more often was associated with higher fat intake. Having a spouse or family member shop with/for the participant was also associated with higher fat intake $(\rho=-0 \cdot 265, P<0 \cdot 001, n 227)$. Fibre intake was weakly correlated with IMD score $(\rho=-0 \cdot 162, P=0 \cdot 019, n$ 209), indicating an association between lower fibre intake and a higher level of deprivation. The IMD score was also correlated with the mode of transport to the main food 
Table 3 Ease of purchasing and availability of fruit, vegetables and low-fat food products and intakes of fibre, fat and unsaturated fat in $\mathbf{2 4 0}$ older adults aged $\geq 70$ years living in Bristol, UK

\begin{tabular}{|c|c|c|c|}
\hline & Women $(n 115)$ & Men $(n 125)$ & Total $(n 240)$ \\
\hline & $\%$ & $\%$ & $\%$ \\
\hline \multicolumn{4}{|c|}{ Easy to purchase fruit and vegetables } \\
\hline Strongly disagree & $13 \cdot 9$ & $14 \cdot 4$ & $14 \cdot 2$ \\
\hline Somewhat disagree & $11 \cdot 3$ & $7 \cdot 2$ & $9 \cdot 2$ \\
\hline Neutral & $2 \cdot 6$ & $2 \cdot 4$ & $2 \cdot \overline{5}$ \\
\hline Somewhat agree & $17 \cdot 4$ & $19 \cdot 2$ & $18 \cdot 3$ \\
\hline Strongly agree & $53 \cdot 0$ & $56 \cdot 0$ & $54 \cdot 6$ \\
\hline $\mathrm{N} / \mathrm{A}$ & $1 \cdot 7$ & $0 \cdot 8$ & $1 \cdot 2$ \\
\hline \multicolumn{4}{|c|}{ Large selection available of fresh fruit and vegetables } \\
\hline Strongly disagree & $20 \cdot 9$ & $18 \cdot 4$ & $19 \cdot 6$ \\
\hline Somewhat disagree & $12 \cdot 2$ & $11 \cdot 2$ & $11 \cdot 7$ \\
\hline Neutral & $1 \cdot 7$ & $2 \cdot 4$ & $2 \cdot 1$ \\
\hline Somewhat agree & $12 \cdot 2$ & $17 \cdot 6$ & $15 \cdot 0$ \\
\hline Strongly agree & $51 \cdot 3$ & $49 \cdot 6$ & $50 \cdot 4$ \\
\hline N/A & $1 \cdot 7$ & $0 \cdot 8$ & $1 \cdot 2$ \\
\hline \multicolumn{4}{|c|}{ Fresh produce of high quality } \\
\hline Strongly disagree & $18 \cdot 3$ & $16 \cdot 8$ & $17 \cdot 5$ \\
\hline Somewhat disagree & $7 \cdot 8$ & $7 \cdot 2$ & $7 \cdot 5$ \\
\hline Neutral & $10 \cdot 4$ & $12 \cdot 0$ & $11 \cdot 2$ \\
\hline Somewhat agree & $21 \cdot 7$ & $25 \cdot 6$ & $23 \cdot 8$ \\
\hline Strongly agree & $38 \cdot 3$ & $36 \cdot 0$ & $37 \cdot 1$ \\
\hline $\mathrm{N} / \mathrm{A}$ & $3 \cdot 5$ & $2 \cdot 4$ & $2 \cdot 9$ \\
\hline \multicolumn{4}{|c|}{ Easy to purchase low-fat foods } \\
\hline Strongly disagree & $16 \cdot 5$ & $10 \cdot 4$ & $13 \cdot 3$ \\
\hline Somewhat disagree & $7 \cdot 8$ & $8 \cdot 0$ & $7 \cdot 9$ \\
\hline Neutral & $7 \cdot 0$ & $6 \cdot 4$ & $6 \cdot 7$ \\
\hline Somewhat agree & $14 \cdot 8$ & $23 \cdot 2$ & $19 \cdot 2$ \\
\hline Strongly agree & $48 \cdot 7$ & $48 \cdot 0$ & $48 \cdot 3$ \\
\hline $\mathrm{N} / \mathrm{A}$ & $5 \cdot 2$ & $4 \cdot 0$ & $4 \cdot 6$ \\
\hline \multicolumn{4}{|c|}{ Large selection of low-fat products available } \\
\hline Strongly disagree & $19 \cdot 2$ & $15 \cdot 2$ & $17 \cdot 1$ \\
\hline Somewhat disagree & $10 \cdot 4$ & $8 \cdot 0$ & $9 \cdot 2$ \\
\hline Neutral & $8 \cdot 7$ & $16 \cdot 8$ & $12 \cdot 9$ \\
\hline Somewhat agree & $22 \cdot 6$ & $18 \cdot 4$ & $20 \cdot 4$ \\
\hline Strongly agree & 33.9 & $36 \cdot 0$ & $35 \cdot 0$ \\
\hline N/A & $5 \cdot 2$ & $5 \cdot 6$ & $5 \cdot 4$ \\
\hline \multicolumn{4}{|l|}{ Fibre intake } \\
\hline Low & $21 \cdot 7$ & $16 \cdot 8$ & $19 \cdot 2$ \\
\hline Medium & $31 \cdot 4$ & $32 \cdot 8$ & $32 \cdot 1$ \\
\hline High & $33 \cdot 0$ & $38 \cdot 4$ & $35 \cdot 8$ \\
\hline N/A & $13 \cdot 9$ & $12 \cdot 0$ & $12 \cdot 9$ \\
\hline \multicolumn{4}{|l|}{ Fat intake } \\
\hline Low & $40 \cdot 0^{*}$ & $25 \cdot 6$ & $32 \cdot 5$ \\
\hline Medium & $25 \cdot 2^{*}$ & $36 \cdot 8$ & $31 \cdot 3$ \\
\hline High & $14 \cdot 8$ & $17 \cdot 6$ & $16 \cdot 2$ \\
\hline $\mathrm{N} / \mathrm{A}$ & $20 \cdot 0$ & $20 \cdot 0$ & $20 \cdot 0$ \\
\hline \multicolumn{4}{|l|}{ Unsaturated fat intake } \\
\hline Low & $7 \cdot 8$ & $4 \cdot 8$ & $6 \cdot 2$ \\
\hline Medium & $49 \cdot 6$ & $55 \cdot 2$ & $52 \cdot \overline{5}$ \\
\hline High & $40 \cdot 0$ & $38 \cdot 4$ & $39 \cdot 2$ \\
\hline N/A & $2 \cdot 6$ & $1 \cdot 6$ & $2 \cdot \overline{1}$ \\
\hline
\end{tabular}

$\mathrm{N} / \mathrm{A}$, data not available.

*Significant difference between genders.

shopping venue $(\rho=0 \cdot 290, P<0 \cdot 001, n 170)$, indicating that those with a higher level of deprivation were less likely to drive or be driven to their main food shopping venue.

\section{Discussion}

The present study makes an important contribution to the limited published literature related to food shopping habits of older adults, particularly of the subgroup aged $\geq 70$ years, and their relationship with selected healthrelated indicators. The sample included 240 participants from across the socio-economic and amenities-access spectrums in Bristol, UK. The sample is reasonably representative of older adults in the UK in relation to weight status and prevalence of common disease conditions.

Most OPAL participants reported food shopping by themselves or with another person, with men more likely 
Table 4 Spearman's rank order correlations between BMI, general health, physical function, physical activity levels (steps/d) and food shopping habits among 240 older adults aged $\geq 70$ years living in Bristol, UK

\begin{tabular}{|c|c|c|c|c|c|c|c|c|c|c|c|}
\hline & BMI $\left(\mathrm{kg} / \mathrm{m}^{2}\right)$ & $\begin{array}{l}\text { General } \\
\text { health }\end{array}$ & $\begin{array}{l}\text { Physical } \\
\text { function }\end{array}$ & $\begin{array}{l}\text { Physical } \\
\text { activity } \\
\text { (steps/d) }\end{array}$ & $\begin{array}{l}\text { Minutes taken to } \\
\text { reach the main } \\
\text { food shopping } \\
\text { venue }\end{array}$ & $\begin{array}{l}\text { Frequency of } \\
\text { use of the main } \\
\text { food shopping } \\
\text { venue }\end{array}$ & $\begin{array}{l}\text { Easy to } \\
\text { purchase } \\
\text { fruit and } \\
\text { vegetables }\end{array}$ & $\begin{array}{l}\text { Large } \\
\text { selection of } \\
\text { fruit and } \\
\text { vegetables }\end{array}$ & $\begin{array}{l}\text { High-quality } \\
\text { produce }\end{array}$ & $\begin{array}{l}\text { Easy to } \\
\text { purchase } \\
\text { low-fat } \\
\text { products }\end{array}$ & $\begin{array}{l}\text { Large } \\
\text { selection } \\
\text { of low-fat } \\
\text { products }\end{array}$ \\
\hline BMI $\left(\mathrm{kg} / \mathrm{m}^{2}\right)$ & 1.00 & - & - & - & - & - & - & - & - & - & - \\
\hline $\begin{array}{l}\text { General health } \\
P \\
n\end{array}$ & $\begin{array}{l}0 \cdot 105 \\
0 \cdot 109 \\
235\end{array}$ & $1 \cdot 00$ & - & - & - & - & - & - & - & - & - \\
\hline $\begin{array}{l}\text { Physical function } \\
P \\
n\end{array}$ & $\begin{aligned}-0 \cdot 115 \\
0.075 \\
240\end{aligned}$ & $\begin{array}{c}-0 \cdot 374 \\
0 \cdot 001 \\
235\end{array}$ & $1 \cdot 00$ & - & - & - & - & - & - & - & - \\
\hline $\begin{array}{l}\text { Physical activity (steps/d) } \\
P \\
n\end{array}$ & $\begin{array}{c}-0.202 \\
0.002 \\
222\end{array}$ & $\begin{array}{c}-0.365 \\
0.001 \\
220\end{array}$ & $\begin{array}{r}0.605 \\
<0.001 \\
222\end{array}$ & $1 \cdot 00$ & - & - & - & - & - & - & - \\
\hline $\begin{array}{l}\text { Minutes taken to reach the } \\
\text { main food shopping venue }\end{array}$ & -0.037 & $0 \cdot 111$ & -0.084 & $-0 \cdot 100$ & $1 \cdot 00$ & - & - & - & - & - & - \\
\hline $\begin{array}{l}P \\
n\end{array}$ & $\begin{array}{l}0 \cdot 637 \\
165\end{array}$ & $\begin{array}{l}0 \cdot 160 \\
161\end{array}$ & $\begin{array}{l}0 \cdot 284 \\
165\end{array}$ & $\begin{array}{l}0 \cdot 222 \\
152\end{array}$ & & & & & & & \\
\hline $\begin{array}{l}\text { Frequency of the use of main } \\
\text { food shopping venue }\end{array}$ & -0.044 & 0.015 & $-0 \cdot 148$ & $-0 \cdot 180$ & 0.376 & $1 \cdot 00$ & - & - & - & - & - \\
\hline $\begin{array}{l}P \\
n\end{array}$ & $\begin{array}{l}0 \cdot 567 \\
170\end{array}$ & $\begin{array}{l}0 \cdot 852 \\
166\end{array}$ & $\begin{array}{l}0.055 \\
170\end{array}$ & $\begin{array}{l}0.024 \\
157\end{array}$ & $\begin{array}{c}<0.001 \\
165\end{array}$ & & & & & & \\
\hline $\begin{array}{l}\text { Easy to purchase fruit and } \\
\text { vegetables }\end{array}$ & 0.015 & $-0 \cdot 210$ & $0 \cdot 211$ & $0 \cdot 238$ & $-0 \cdot 245$ & -0.061 & $1 \cdot 00$ & - & - & - & - \\
\hline $\begin{array}{l}P \\
n\end{array}$ & $\begin{array}{l}0 \cdot 820 \\
237\end{array}$ & $\begin{array}{l}0 \cdot 001 \\
235\end{array}$ & $\begin{array}{l}0 \cdot 001 \\
237\end{array}$ & $\begin{array}{c}\leq 0 \cdot 001 \\
221\end{array}$ & $\begin{array}{l}0.002 \\
162\end{array}$ & $\begin{array}{l}0 \cdot 430 \\
167\end{array}$ & & & & & \\
\hline $\begin{array}{l}\text { Large selection of fruit and } \\
\text { vegetables }\end{array}$ & -0.031 & $-0 \cdot 226$ & $0 \cdot 182$ & $0 \cdot 171$ & $-0 \cdot 242$ & 0.004 & 0.854 & $1 \cdot 00$ & - & - & - \\
\hline $\begin{array}{l}P \\
n\end{array}$ & $\begin{array}{l}0.634 \\
237\end{array}$ & $\begin{array}{l}\leq 0 \cdot 001 \\
235\end{array}$ & $\begin{array}{l}0.005 \\
237\end{array}$ & $\begin{array}{l}0 \cdot 011 \\
221\end{array}$ & $\begin{array}{l}0.002 \\
162\end{array}$ & $\begin{array}{l}0.956 \\
167\end{array}$ & $\begin{array}{c}<0 \cdot 001 \\
237\end{array}$ & & & & \\
\hline $\begin{array}{l}\text { High-quality produce } \\
P \\
n\end{array}$ & $\begin{array}{c}-0.035 \\
0.592 \\
233\end{array}$ & $\begin{array}{c}-0 \cdot 176 \\
0 \cdot 007 \\
231\end{array}$ & $\begin{array}{r}0.229 \\
<0.001 \\
233\end{array}$ & $\begin{array}{l}0 \cdot 131 \\
0 \cdot 054 \\
217\end{array}$ & $\begin{array}{l}-0 \cdot 295 \\
\leq 0 \cdot 001 \\
159\end{array}$ & $\begin{array}{l}0.035 \\
0.659 \\
164\end{array}$ & $\begin{array}{r}0.765 \\
<0.001 \\
\end{array}$ & $\begin{array}{r}0.816 \\
<0.001\end{array}$ & $1 \cdot 00$ & - & - \\
\hline $\begin{array}{l}n \\
\text { Easy to purchase low-fat } \\
\text { products }\end{array}$ & $\begin{array}{l}233 \\
0.032\end{array}$ & $\begin{array}{c}231 \\
-0 \cdot 259\end{array}$ & $\begin{array}{l}233 \\
0 \cdot 163\end{array}$ & $\begin{array}{l}217 \\
0 \cdot 188\end{array}$ & $\begin{array}{c}159 \\
-0 \cdot 265\end{array}$ & $\begin{array}{l}164 \\
0.000\end{array}$ & $\begin{array}{l}233 \\
0.650\end{array}$ & $\begin{array}{l}233 \\
0.683\end{array}$ & 0.666 & $1 \cdot 00$ & - \\
\hline $\begin{array}{l}P \\
n\end{array}$ & $\begin{array}{l}0 \cdot 628 \\
229\end{array}$ & $\begin{array}{l}\leq 0 \cdot 001 \\
227\end{array}$ & $\begin{array}{l}0 \cdot 013 \\
229\end{array}$ & $\begin{array}{l}0 \cdot 006 \\
214\end{array}$ & $\begin{array}{l}0 \cdot 001 \\
156\end{array}$ & $\begin{array}{l}0.999 \\
161\end{array}$ & $\begin{array}{c}<0.001 \\
229\end{array}$ & $\begin{array}{l}<0.001 \\
229\end{array}$ & $\begin{array}{l}<0.001 \\
227\end{array}$ & & \\
\hline $\begin{array}{l}\text { Large selection of low-fat } \\
\text { products }\end{array}$ & 0.020 & -0.223 & 0.224 & $0 \cdot 157$ & -0.293 & 0.006 & 0.673 & $0 \cdot 728$ & $0 \cdot 718$ & 0.842 & $1 \cdot 00$ \\
\hline$P$ & $\begin{array}{l}0 \cdot 765 \\
227\end{array}$ & $\begin{array}{l}0.001 \\
225\end{array}$ & $\begin{array}{l}0 \cdot 001 \\
227\end{array}$ & $\begin{array}{l}0 \cdot 023 \\
212\end{array}$ & $\begin{array}{c}<0.001 \\
156\end{array}$ & $\begin{array}{l}0.935 \\
161\end{array}$ & $\begin{array}{l}<0 \cdot 001 \\
227\end{array}$ & $\begin{array}{l}<0.001 \\
227\end{array}$ & $\begin{array}{l}<0 \cdot 001 \\
225\end{array}$ & $\begin{array}{l}<0.001 \\
226\end{array}$ & \\
\hline
\end{tabular}


to shop with their spouse and women more likely to shop alone. Supermarkets were the most common shops frequented, with the majority shopping at one of the 'Big 4' supermarket chains in the UK or at an upmarket national chain. In addition, the car was the predominant mode of transport to food shops, with men more likely to drive and women more likely to be driven. This pattern of food shopping is consistent with the current location of various food shops in the UK being further away from local neighbourhoods, and suggests a cultural norm towards conducting one large food shop per week. The use of the car is not surprising, as almost half of the participants reported their main food shopping venue to be located at a distance of at least a 30 min walk. Predominance of car use may indicate an ability to maintain independence to do their own shopping, and help older adults avoid the challenges inherent in carrying heavy loads of groceries that those who actively commute experience. Those OPAL participants who tended to actively commute (i.e. by taking the bus, walking or cycling) to their food shopping venue reported a greater frequency of use of their food shop. This probably reflects ease of access and the necessity to limit the weight of purchases to be carried home. Unfortunately it was not possible to link the perceived walking distance to the nearest food shop with the accelerometer data, and thus it is not clear how much food shopping per se may have contributed to daily physical activity levels in this sample.

Approximately $80 \%$ of participants reported infrequently or never' using restaurants, fast-food outlets or pubs, suggesting that food shopping and cooking at home are critical factors to help older adults meet the needs of their dietary intake. Studies indicate that older adults in Scotland, Sweden and Australia prefer to consume 'proper' meals cooked at home on a regular schedule and many expressed a view that convenience foods are unhealthy and only a reasonable option for people with limitations in preparing and cooking food ${ }^{(27-29)}$.

Although over half of the participants reported that it was easy to purchase a large selection of fresh fruit, vegetables and low-fat foods of high quality, up to $25 \%$ did not agree. Those who reported a stronger disagreement with the ease of purchasing, extent of selection and quality of fruit, vegetables and low-fat products were more likely to report walking for a higher number of minutes to their main food shop. Morland and Filomena ${ }^{(30)}$ found that for every mile travelled to their main food shop, older adults in the USA reported an increase of 0.03 servings of fruit and vegetables/d. These researchers concluded that fruit and vegetables were not locally available and thus those who travelled further were able to access and consume higher amounts of these foods. The OPAL study is cross-sectional; hence, it was not possible to determine causality between distance travelled to the main food shop and purchase and consumption of fruit, vegetables and low-fat products. It is plausible that those who travelled further to their main food shop did so because these food shops carried a larger amount and better quality of fruit, vegetables and low-fat products. Interestingly, in the present study, there were no associations between intake of fibre or fat and type of food shop frequented or the reported ease of purchasing a large selection of highquality fresh fruit, vegetables and low-fat foods. There were significant associations between higher levels of deprivation, lower fibre intake and reduced use of a car to conduct food shopping. These findings suggest that those with limited resources are less likely to drive or be driven to their main food shopping venue and are less likely to choose higher-fibre foods such as fruit, vegetables and whole grains, possibly because of higher cost and/or challenges related to carrying these food items. The consumption of adequate fruit, vegetables and wholegrain foods is imperative to preventing malnutrition in older adults, as there is growing evidence that the low intakes of micronutrients found in these foods, such as vitamins $\mathrm{C}$ and $\mathrm{E}$, carotenoids and folate, are significantly associated with increased risk of frailty in older adults ${ }^{(31-33)}$.

It is of concern that almost $20 \%$ of OPAL participants reported a low fibre intake, as fibre is critical to optimising bowel function and is known to reduce the risk of diverticulitis and perhaps of certain cancers ${ }^{(34)}$. The high fat intake observed in approximately $16 \%$ of participants is also of concern, and combined with the low levels of physical activity in this sample ${ }^{(15)}$ could be the contributing factor to the relatively high levels of overweight and obesity in this sample. A higher fat intake was weakly but significantly associated with food shopping more frequently, and with having a spouse or family member shop with or for the participant. Shopping more often could allow for an increased opportunity to buy favourite, higher-fat foods more often. This correlation may be a reflection of the fact that, in this sample, women reported lower fat intakes than men and were more likely to shop alone than with a spouse or family member. There was also a weak association between higher fat intake and lower BMI; this finding suggests an under-reporting of dietary fat in those who are overweight or obese, which has been reported in the literature ${ }^{(35)}$.

The strong inter-correlations between ease of purchasing, extent of selection and quality of fresh fruit, vegetables and low-fat foods suggest that the main food shopping venues, which tended to be large supermarket chains in the present study, provide a wide variety of high-quality healthy food products. Higher levels of physical function and physical activity and better selfreported general health were significantly but weakly correlated with these food shopping variables. Although these results may suggest that those who were more physically active and healthy were able to maintain their independence, which allowed them to frequent shops with higher food quality and availability, they should be viewed with caution as the relationship may be 
confounded by other factors such as the IMD score of the neighbourhood or socio-economic status. It is recognised, however, that maintaining independence is paramount in older adults, particularly in relation to food-related activities of daily living, as greater independence in food-related activities such as food shopping and meal preparation has been shown to be significantly associated with fewer health problems, greater physical strength and better food intake in older adults ${ }^{(36)}$.

The present study has a number of limitations. Although the sample fairly represented the national IMD distribution, it was not fully representative of older adults living in the UK in relation to formal education and ethnicity. Participants were more educated than the average adult in this age range in the UK, approximately $20 \%$ of whom have not completed secondary education. It is estimated that $>50 \%$ of $70-74$-year-old adults in the UK have no formal qualification $^{(37)}$. In addition, this sample was not representative of the black and ethnic minority (BME) groups in Bristol or the UK, as only $3.3 \%$ of our sample reported being from a BME community; the BME population of Bristol is estimated at $8 \cdot 2 \%{ }^{(38)}$, whereas that of the UK is $7 \cdot 9 \%{ }^{(39)}$. It is not surprising that we were unable to recruit more people from BME communities, as it has been recognised that using methods of recruitment found to be useful for recruiting white participants into research do not translate into successful recruitment of ethnic minority participants ${ }^{(40,41)}$. The strengths of the present study include the collection of a wide array of high-quality data related to food shopping and health-related indicators and the objective assessment of physical activity, physical function and BMI in a relatively large sample of community-dwelling older adults aged $\geq 70$ years.

To conclude, the present study contributes information about food shopping habits and their associations with select health-related indicators among adults $\geq 70$ years of age living in the UK. Results indicate that, in this independent and free-living sample, most shop by themselves or with someone else at large supermarket chains at least once weekly, and the primary mode of transport to food shopping is by car. Although most participants agreed that it was easy to purchase a wide selection of quality fruit, vegetables and low-fat products, a subsample reported low fibre and high fat intakes that were of concern. These results further substantiate the importance of promoting a high-quality diet and regular physical activity in maintaining independence and optimising health in older adults.

\section{Acknowledgements}

The present study was supported by the National Prevention Research Initiative (Grant no. G0501312; http:// www.npri.org.uk) whose funding partners are the British Heart Foundation; Cancer Research UK; Department of
Health; Diabetes UK; Economic and Social Research Council; Medical Research Council; Research and Development Office for the Northern Ireland Health and Social Services; Chief Scientist Office, Scottish Executive Health Department; Welsh Assembly Government; and World Cancer Research Fund. The authors have no conflict of interest to declare. All drafts of the paper were prepared by J.L.T. with inputs from all co-authors. Statistical analyses were executed by J.L.T. All authors have reviewed and approved the final version. The authors thank the participants and general medical practices for giving their time and energy to the study. The authors also acknowledge all the investigators and Project OPAL team members not listed as co-authors.

\section{References}

1. World Health Organization (2002) Active Ageing: A Policy Framework. Geneva: WHO; available at http://whqlibdoc. who.int/hq/2002/WHO_NMH_NPH_02.8.pdf

2. Bray H (2008) 2006-based national population projections for the UK and constituent countries. Population Trends 131, 8-18.

3. Dini E \& Goldring S (2008) Estimating the changing population of the 'oldest old'. Population Trends 132, 8-16.

4. Office of National Statistics (2006) Focus on health: limiting illness. http://www.statistics.gov.uk/cci/nugget.asp?id=1326 (accessed January 2011).

5. Booth FW, Chakravarthy MV, Gordon SE et al. (2002) Waging war on physical inactivity: using modern molecular ammunition against an ancient enemy. J Appl Physiol 93, 3-30.

6. Roberts CK \& Barnard RJ (2005) Effects of exercise and diet on chronic disease. J Appl Physiol 98, 3-30.

7. British Association for Parenteral and Enteral Nutrition (2006) Malnutrition among Older People in the Community: Policy Recommendations for Change. London: European Nutrition for Health Alliance; available at http://www.bapen. org.uk/pdfs/malnut_in_the_community.pdf

8. The Information Centre, National Health Service (2008) Health Survey for England 2006: Cardiovascular Disease and Risk Factors in Adults. Leeds: The Information Centre; available at http://www.ic.nhs.uk/pubs/hse06cvdandriskfactors

9. Brownie S (2006) Why are elderly individuals at risk of nutritional deficiency? Int J Nurs Pract 12, 110-118.

10. McKie L (1999) Older people and food: independence, locality and diet. Br Food J 101, 528-536.

11. Rioux L (2005) The well-being of aging people living in their own homes. J Environ Psychol 25, 231-243.

12. Herne S (1995) Research on food choice and nutritional status in elderly people: a review. Br Food J 97, 12-29.

13. Smith GC (1991) Grocery shopping patterns of the ambulatory urban elderly. Environ Behav 23, 86-114.

14. Smith GC \& Gauthier JJ (1995) Evaluation and utilization of local service environments by residents of low rent senior citizen apartments. Can J Urban Res 4, 305-323.

15. Davis MG, Fox KR, Hillsdon M et al. (2011) Objectively measured physical activity in a diverse sample of older urban UK adults. Med Sci Sports Exerc 43, 647-654.

16. Noble M, Wright G, Dibben C et al. (2004) The English Indices of Deprivation 2004. Oxford: Social Disadvantage Research Centre.

17. Shigematsu R, Sallis JF, Conway TL et al. (2009) Age differences in the relation of perceived neighborhood environment to walking. Med Sci Sports Exerc 41, 314-321. 
18. Saelens BE, Sallis JF, Black JB et al. (2003) Neighborhoodbased differences in physical activity: an environment scale evaluation. Am J Public Health 93, 1552-1558.

19. United States Department of Agriculture, Economic Research Service (2000) Briefing Rooms. Food Security in the United States: Household Survey Tools. Alexandria, VA: USDA/ERS; available at http://www.ers.usda.gov/Briefing/FoodSecurity/ surveytools.htm

20. Ware JE, Kosinski M \& Keller SD (1996) A 12-item shortform health survey: construction of scales and preliminary tests of reliability and validity. Med Care 34, 220-233.

21. Roe L, Strong C, Whiteside C et al. (1994) Dietary intervention in primary care: validity of the DINE methods for diet assessment. Fam Pract 11, 375-381.

22. Guralnik JM, Simonsick EM, Ferrucci L et al. (1994) A short physical performance battery assessing lower extremity function: association with self-reported disability and prediction of mortality and nursing home admission. J Gerontol 49, 85-94.

23. The Information Centre, National Health Service (2009) Health Survey for England - 2008 Trend Tables. http:// www.ic.nhs.uk/pubs/hse08trends (accessed January 2011)

24. Fox KR, Hillsdon M, Sharp D et al. (2011) Neighbourhood deprivation and physical activity in UK older adults. Health Place 17, 633-640.

25. The Information Centre, National Health Service (2008) Health Survey for England 2006: CVD and risk factors in adults. http://www.ic.nhs.uk/pubs/hse06cvdandriskfactors (accessed April 2011).

26. Office for National Statistics (2006) Focus on Health. Morbidity. Arthritis More Common in Women. Newport: ONS; available at http://www.statistics.gov.uk/cci/nugget. asp?id $=1331$

27. McKie L, MacInnes A, Hendry J et al. (2000) The food consumption patterns and perceptions of dietary advice of older people. J Hum Nutr Diet 13, 173-183.

28. Gustafsson K \& Sidenvall B (2002) Food-related health perceptions and food habits among older women. $J$ Adv Nurs 39, 164-173.
29. Hunter W \& Worsley T (2009) Understanding the older food consumer. Present day behaviours and future expectations. Appetite 52, 147-154.

30. Morland K \& Filomena S (2008) The utilization of local food environments by urban seniors. Prev Med 47, 289-293.

31. Bartali B, Frongillo EA, Bandinelli S et al. (2006) Low nutrient intake is an essential component of frailty in older persons. J Gerontol 61A, 589-593.

32. Semba RD, Bartali B, Zhou J et al. (2006) Low serum micronutrient concentrations predict frailty among older women living in the community. J Gerontol 61A, 594-599.

33. Michelon E, Blaum C, Semba R et al. (2006) Vitamin and carotenoid status in older women: associations with the frailty syndrome. J Gerontol 61A, 600-607.

34. World Cancer Research Fund/American Institute for Cancer Research (2007) Food, Nutrition, Physical Activity, and the Prevention of Cancer: A Global Perspective. Washington, DC: AICR.

35. Heitmann BL \& Lissner L (1995) Dietary underreporting by obese individuals - is it specific or non-specific? BMJ 311, 986-989.

36. Keller HH (2005) Reliance on others for food-related activities of daily living. J Nutr Elderly 25, 43-59.

37. Office for National Statistics (2005) Focus on Older People 2005. http://www.statistics.gov.uk/StatBase/Product. asp?vlnk $=12348$

38. Office for National Statistics (2004) Focus on Ethnicity \& Identity. http://www.statistics.gov.uk/cci/nugget.asp?id=455

39. Office for National Statistics (2004) Neighbourhood Statistics. http://neighbourhood.statistics.gov.uk/dissemination/

40. Areán PA \& Gallagher-Thompson D (1996) Issues and recommendations for the recruitment and retention of older ethnic minority adults into clinical research. J Consult Clin Psychol 64, 875-880.

41. Sheikh A, Halami L, Bhopal R et al. (2009) Facilitating the recruitment of minority ethnic people into research: qualitative case study of South Asians and asthma. PLoS Med 6, e1000148. 